\title{
Diabetes, Heart Disease, Fatty Liver, Blood Groups And COVID-19 Disease: A Brief Review of Evidence
}

\author{
Mohammad Yavari', Maryam Mahdavi Afshar ${ }^{2}$, Fateme jabalameli ${ }^{3}$, Parinaz sadeghpoor \\ kharkani $^{4}$, Negar Mohammad jafari ${ }^{5}$, Sanaz sadeghpoor kharkani ${ }^{6}$, Zahra Eskandarian ${ }^{7}$, \\ Golnar Kamyar ${ }^{8}$, Hossein Esmaeilii ${ }^{9 *}$, Muzzammil Ahmadzada ${ }^{10}$ \\ ${ }^{1}$ Bachelor of Science in Nursing, Islamic Azad University Tehran Branch, Tehran, Iran
}

${ }^{2}$ Young Researcher and Elite Clube, Tehran Medical Sciences, Islamic Azad University, Tehran, Iran

${ }^{3}$ Medical Student, Department of Medicine, Islamic Azad University Tehran Medical Sciences, Iran

${ }^{4}$ Young Researcher and Elite Clube, Tehran Medical Sciences, Islamic Azad University, Tehran, Iran

${ }^{5}$ B.Sc. in Radiology, Department of Allied medical sciences, Iran university of medical science

${ }^{6} \mathrm{MD}$, Shahid Beheshti University of Medical Sciences, Tehran, Iran

${ }^{7}$ Dentistry student, Semmelweis university, Faculty of dentistry, Budapest, Hungary

${ }^{8}$ Medical Student, Tehran University of Medical Sciences, Tehran, Iran

${ }^{9}$ Young Researchers and Elite Club, Medical Department, Tehran Medical Sciences, Islamic Azad University, Tehran, Iran

${ }^{10}$ Johns Hopkins University, 3500 N Charles St, Baltimore MD 21218

*Corresponding author: Hossein Esmaeili, Young Researchers and Elite Club, Medical Department, Tehran Medical Sciences, Islamic Azad University, Tehran, Iran.

To Cite This Article: Mohammad Yavari, Maryam Mahdavi Afshar, Fateme jabalameli, Parinaz sadeghpoor kharkani, Hossein Esmaeili, et al., Diabetes, Heart Disease, Fatty Liver, Blood Groups And COVID-19 Disease: A Brief Review of Evidence. Am J Biomed Sci \& Res. 2021 - 13(2). AJBSR.MS.ID.001854. DOI: 10.34297/AJBSR.2021.13.001854.

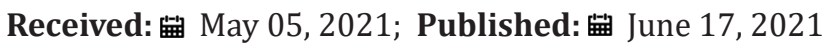

\begin{abstract}
SARS-CoV-2 infection can have a severe evolution and complications in people who present comorbidities. Indeed, people with diabetes, especially those with type 1, and COVID19 are exposed to and an increased risk of diabetic ketoacidosis. Also, cardiac complications due to coronary heart disease or other cardiovascular one, such as hypertension, are possible. These complications may be caused by the virus entering cardiomyocytes or even other surrounding cells. In people with fatty liver/hepatic impairment and COVID-19, there is an increased expression of ACE2 receptors through the HEK293 cell line, which allows SARS-CoV-2 to enter the cells through the TMPRSS2 interface with the help of the regulatory protein PIKFYE, by therefore increasing the severity of the disease. Moreover SARS-CoV-2 after entry causes T-cell CD8 + reaction, which leads to liver cell damage. The incidence of COVID-19 seems to be high in people with blood group A and low in those with blood group 0. For this reason, the aim of this review is to summarize evidence of main metabolic comorbidities (diabetes, cardiovascular diseases, and liver diseases) and blood groups and COVID-19.
\end{abstract}

Keywords: SARS-Cov-2; Diabetes; Cardiovascular Diseases; Liver Diseases; Metabolic; Corona Virus2; Respiratory; Blood Group; Pneumonia; Hypoxia Occurs; Patients

Abbreviations: ICNARC: Intensive Care National Audit and Research Centre; BMI: Body mass index; NAFLD: Non-Alcoholic Fatty Liver Disease; MAFLD: Metabolic-Associated Fatty Liver Disease; RT-PCR: Reverse transcription polymerase chain reaction; LDH: Lactate Dehydrogenase; DPP4 Dipeptidyl-peptidase 4; AST: aspartate aminotransferase; ALT: alanine aminotransferase; ACE: angiotensin-converting enzyme; VTE: venous thromboembolism; VWF: von Willebrand factor; ICAM: intracellular adhesion molecule. 


\section{Introduction}

It has been over a year since the Severe Acute Respiratory Syndrome Corona Virus 2 (SARS-CoV2-) originated into China and rapidly spread around the world, causing a terrible pandemic. The incidence and severity of Coronavirus Disease 19 (COVID-19) depends on a variety of factors [REF]. It has been shown how elderly, diabetic people, those with cardiovascular and liver diseases are more likely to develop a severe form of COVID-19. Also, some a relationship between blood group and severity of COVID-19 has been established. Quite often, people present multimorbidity that further increases risk of COVID-19-related complications [1-3]. During pandemic, clinical studies have shown that obese patients become infected by SARS-CoV-2 earlier than the general population and experience severe illnesses more frequently requiring intubation $[4,5]$. The ICNARC in the United Kingdom reported that $38 \%$ of patients with COVID-19 admitted to the Intensive Care Units (ICU) were obese [6]. BMI> 35 were 3.6 times more likely to be admitted to the ICU than patients with a BMI <30 [7]. It should be noted that obesity itself is the cause of cardiovascular disease [8], which is itself a risk factor for severe coronary heart disease $[9,10]$. People with coronavirus may develop some cardiovascular disease.
If people with coronavirus develop pneumonia, hypoxia occurs, which in turn causes anaerobic fermentation and increased intracellular acidity, and ultimately radical Free radicals damage cell membranes, heart cells, and the secretion of catecholamine's in these patients due to stress causes hypertension, which can cause serious problems for the heart tissue. However, a history of hypertension before contracting the virus can predispose to Cause more problems in these patients [11,12]. Non-Alcoholic Fatty Liver Disease (NAFLD) is another important risk factor in increasing the severity of COVID-19 because cytokines are high in these people and in case of COVID-19 the effects of the disease are doubled. Also due to the active inflammatory pathways in these patients the coronavirus can cause Hepatic fibrosis therefore has a direct relationship between NAFLD and Covid-19 and the effects of Covid-19 are more severe in these individuals $[13,14]$. It should be noted that the severity of Covid-19 virus disease is related to people with MAFLD, so that people with MAFLD spend more time in the hospital [15]. It should also be noted the incidence of symptoms of COVID-19disease is related to the patient's blood type [16]. The function and effects of this virus may not be clear yet, but according to the studies that have been done, in this article we tried to review the relationship between diabetes, cardiovascular disease, fatty liver and blood groups with COVID-19.

\section{Recent Findings on Diabetes as A Comorbidity for Covid-19}

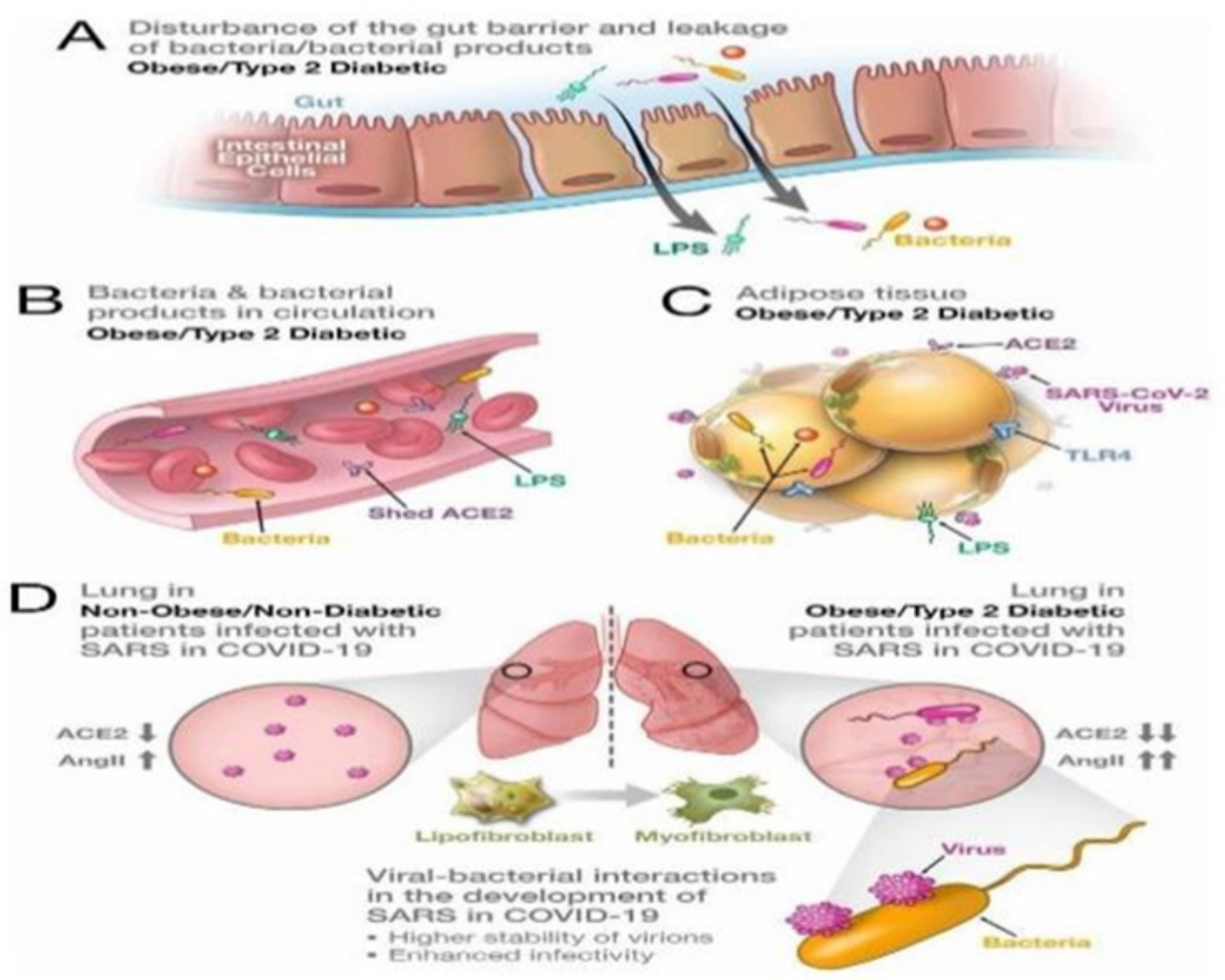

Figure 1: Diabetes and obesity are two comorbidities in Covid-19. 
COVID-19 virus from the coronavirus family can be transmitted through aerosol, direct contact, and respiratory droplets of cough and sneezing [17]. Transmission of people with asymptomatic virus during incubation is high [18]. Risk factors such as age (older age), sex (males) and ethnicity (black and Hispanic) are involved in disease severity and mortality [19,20]. All people with underlying diseases such as diabetes, hypertension, chronic kidney disease, cancers, people with immunodeficiency and people with cardiovascular disease who have symptoms (high fever and respiratory symptoms) Such as cough and shortness of breath) are a priority in RT-PCR and should be evaluated for SARS-COV-2 [21] (Figure1). Diabetes mellitus, which is a systemic disease, affects the response of the human immune system to infectious agents. During diabetic syndrome, hyperglycemia and insulin resistance cause the release of pro-inflammatory cytokines and stimulate the production of adhesion molecules [22]. High plasma glucose during uncontrolled diabetes in patients with COVID-19, along with severe reductions in FEV1 and FVC, cause respiratory distress and damage to pulmonary epithelial cells [23]. Diabetes alone cannot increase a person's risk of get SARS-CoV-2 infection but it can exacerbate the COVID-19 and increase the severity of symptoms [24]. Previous study findings indicated that the incidence of COVID-19 disease in diabetic patients is the same as the non-diabetic population [23].

In a Chinese study conducted on 3 groups of patients (80 patients without coronary artery disease, 76 non-diabetic patients with coronary artery disease, 55 diabetic patients with coronary artery disease), authors found that there was no difference in the level of white blood cells and liver enzymes, but the number of lymphocytes and albumin in patients with coronary artery disease was significantly higher than the other two groups. LDH levels increase in most respiratory diseases, including Covid-19. And is one of the aggravating factors of respiratory diseases $[25,26]$. Diabetics are always at risk for various infections and impaired immune responses [27]. Storms of cytokines and lymphopenia are effective in exacerbating Covid disease and given that inflammatory mediators are active in patients with coronary artery by inhibiting their dominant pathways such as DPP4, they can prevent T lymphocytes from proliferating and producing inflammatory cytokines [28]. The NF-KAPPA-BETA pathway plays an important role in the attack of cytokines, and in the case of COVID 19, inflammation is seen through this pathway. By suppressing this pathway through SITAGLIPTIN, which is a DPP4 inhibitor, Controlled inflammation caused by the virus [29]. Following the COVID-19 pandemic, in most parts of the world we saw quarantine of all individuals seeking relative improvement.

According to a cross-sectional study of patients with type 1 diabetes, they found that control of blood sugar in diabetic patients decreased during this period. It was severe and was measured irregularly, which can be attributed to patients' lack of access to insulin and needed medications, poor diet, and less physical activity [30]. In another study, the effect of quarantine and psychological factors of this period on patients with diabetes was investigated. According to available information, COVID-19 disease causes overeating in diabetics and consequently reduces blood sugar control in these people Slowly [31]. Meanwhile, many diabetic patients who do not have coronary artery disease are concerned with managing the disease and controlling it if it occurs [32]. One of the effective factors that increase anxiety and consequently decrease the immune system of a diabetic person against various infections such as COVID-19, can be loneliness and lack of social communication during this period, worry about reduced access to insulin. The need in case of quarantine and lack of support from care and medical teams [33]. Possible interventions for monitoring diabetic patients during quarantine include proper screening, referral of patients for psychological problems to relevant clinics and centers, proper diets, and regular blood sugar control [34].

D-dimer is a small protein that appears in the blood following the destruction of a blood clot (thrombus) by fibrinolysis, and its presence in the blood in COVID-19 disease indicates a worsening of the disease and an increase in coagulation. In a group of patients with COVID-19, the concentration of D-dimer in the blood of diabetics was $1509 \mathrm{mg} / \mathrm{ml}+$ _1509 and in non-diabetics was 624 +_515 mg/ml, which was found to be diabetic in COVID-19, level D- had higher dimers than non-diabetics and D-dimer levels above $2000 \mathrm{ng} / \mathrm{ml}$ resulted in increased mortality [35]. As a result, the association of COVID-19 with diabetes due to glycosylation of hemoglobin leads to excessive coagulation [36]. To diagnose Gestational Diabetes Mellitus (GDM), we use the Oral Glucose Tolerance Test (OGTT) [37]. Due to the increased risk of COVID-19 by attending health centers, this test is performed less than before and a suitable alternative for this test is measuring $\mathrm{HbA1c} 41 \mathrm{mmol} /$ mol (5.9\%) in 24 to 28 weeks of pregnancy Is [38].

According to a study conducted by an article at Ican School of Medicine in Mount Sinai, New York, they found that the mortality rate of diabetic patients with COVID-19 is higher than that of cardiovascular patients and cancer patients with COVID disease. MERS and SARS viruses can also be generalized [39]. Diabetes along with obesity is a very important risk factor among patients with COVID-19 [40]. A study of 450 eligible patients admitted to the Massachusetts General Hospital (MGH) between March 11 and April 30, 2020, found that the number of patients with COVID-19 diabetes in the ICU, as well as mortality Most non-diabetic patients had COVID-19. High BMI with diabetes also increased the severity of the disease [41].

ACE2 is an anti-inflammatory receptor suitable for the invasion of SARS-COV-2 and CORONAVIRUS in human cells, which due to 
decreased glycosylation in diabetics, its expression is reduced and provides the basis for ARDS [42]. SARS-COV-2 is also able to destroy pancreatic islet cells, which further reduces insulin and worsens the condition for diabetics, especially type 1 diabetics [43]. The results of a study conducted in South Korea on 211 patients with COVID-19 showed that the severity and severity of COVID-19 symptoms in diabetic patients was approximately 60 times higher than in nondiabetic patients due to reduced immune cell function. And the increase in blood glucose was progressive [44].

Hyperglycemia, which means an abnormal rise in blood sugar, increases the risk of death from pneumonia, heart attack, injury and similar injuries seen in patients with COVID-19 due to an increase in TNF-ALPHA, a major cause of increased ICU hospitalization and Mortality from hyperglycemic patients has been higher than diabetes mellitus [45]. Also, SARS-COV-2 infection, following the destruction of pancreatic islets and beta cells, reduces insulin secretion and causes uncontrolled and excessive increase in blood sugar [46]. In other articles, high levels of dimer, which causes microscopic venous clots in various parts of the body, especially the brain, following diabetes, high blood pressure, and stroke, are among the reasons for the increased mortality of diabetic patients following COVID-19 Was $[47,48]$. Despite the large number of articles and reviews, there are still doubts about increasing the mortality rate of diabetic patients with COVID-19. According to this study, although anti-diabetic drugs such as metformin improve the condition of patients with SARS-COV- 2 . They are effective but their mortality rate has been measured more than the non-diabetic population [49].

Diabetic blood sugar levels may rise during periods of stress or with COVID-19 and manifest as Diabetic Ketoacidosis (DKA); in this case, the body does not have enough insulin to manage this high blood sugar level. Decomposes fats and acidifies the blood [50]. In the case of COVID-19, if the respiratory problems are so severe that the person needs the help of a device to breathe, in such cases, diabetics should not be prescribed oral diabetes medications and intravenous insulin should be started under the supervision of a physician [51]. However, some studies show the progression and recurrence of coronary heart disease following the use of insulin and the need for mechanical ventilation and hospitalization in the intensive care unit following the use or injection of insulin [52]. Obese diabetics with a BMI of more than 30 experience dangerous complications and severe symptoms of COVID-19 disease following an increase in IL-6, which is a response to excess fat mass [53]. During coronary quarantine, diabetic patients suffered severe wounds due to lack of DFU care and foot hygiene, and unfortunately, we have seen a significant increase in the rate of lower limb amputations in diabetic patients [54]

\section{Side Effects of Coronavirus on Cardiovascular System}

An evaluation was conducted in the Netherlands among 3011 patients with hospitalized COVID-19 in the age range of 67 years with most men (62.8\%) that heart diseases such as atrial fibrillation and heart failure were very common [55]. Different cardiac complications have been observed among coronary heart disease patients. Some studies show that the lack of control of heart rhythm by the main sinus node has the highest incidence [56]. In addition, sinus bradycardia $[57,58]$ and sinus tachycardia $[59,60]$ have been observed among patients. The mechanism of association of this complication with COVID- 19 is not yet fully understood but is likely due to various factors including: decreased ACE2 receptor [61], interaction between sialic acid protein and CD147, hypoxia, direct endocardial damage, fear, and disorder. In the amount of electrolyte and acidity [62-66]. Other causes of cardiac arrhythmia in patients with COVID -19 include side effects of drugs used [67]. In fact, it can be said that cardiac arrhythmias are not simply due to the entry of the virus into the cell and the development of infection [68]. Right ventricular failure was another complication observed in patients with COVID-19. The causes of right ventricular failure include the release of various cytokines and disorders of the reninangiotensin system $[69,70]$. Acute coronary syndrome or impaired blood supply to the heart itself was one of the cardiac complications, but in other studies in countries such as the United States, we saw a significant reduction (half of all) in the admission of patients with this syndrome, which is mostly statistical and its cause. it is not specified yet.

Risk factors for atherosclerosis increase the risk of developing this syndrome [71-73]. This syndrome in turn can cause myocardial infarction [70]. In general, the prevalence of fatal cardiovascular complications in these patients is relatively low, although the background of the heart problem increases the risk [74,75]. Hypersensitive C-reactive protein (hs-CRP) and serum creatinine were observed in more than one study in China The severity and mortality of these patients are directly related [76-78]. A research team in Germany evaluated a group of 40 patients. In this evaluation, a myocardial infarction was observed that could affect left ventricular systole. They can be caused by troponin T software. Other research in China also confirms this [79-81] (Figure2). Fatty liver is said to be one of the risk factors for COVID-19 [82]. There are several types of fatty liver. Among NASH fatty liver types, NAFLD is strongly associated with increased severity of COVID-19 disease [83]. Studies show that people with MAFLD who develop COVID-19 become more acute due to increased expression of ACE2 receptors [84,85] through the HEK293 cell line [86-89]. TMPRSS2 is also a linker for the binding of SARS-COV-2 to the ACE2 receptor, and 
PIKFYE is a regulatory protein used to deliver SARS-COV-2 into cells [86]. We conclude that SARS-COV-2 infection prefers to enter the cell through the ACE2 receptor and become pathogenic [90,91]. Another type of fatty liver, NAFLD, which is known as simple non- alcoholic fatty liver, also increases the severity of the disease in patients with COVID- 19 through macrophages M1 and M2 and by increasing the activity of cells $[93,94]$.

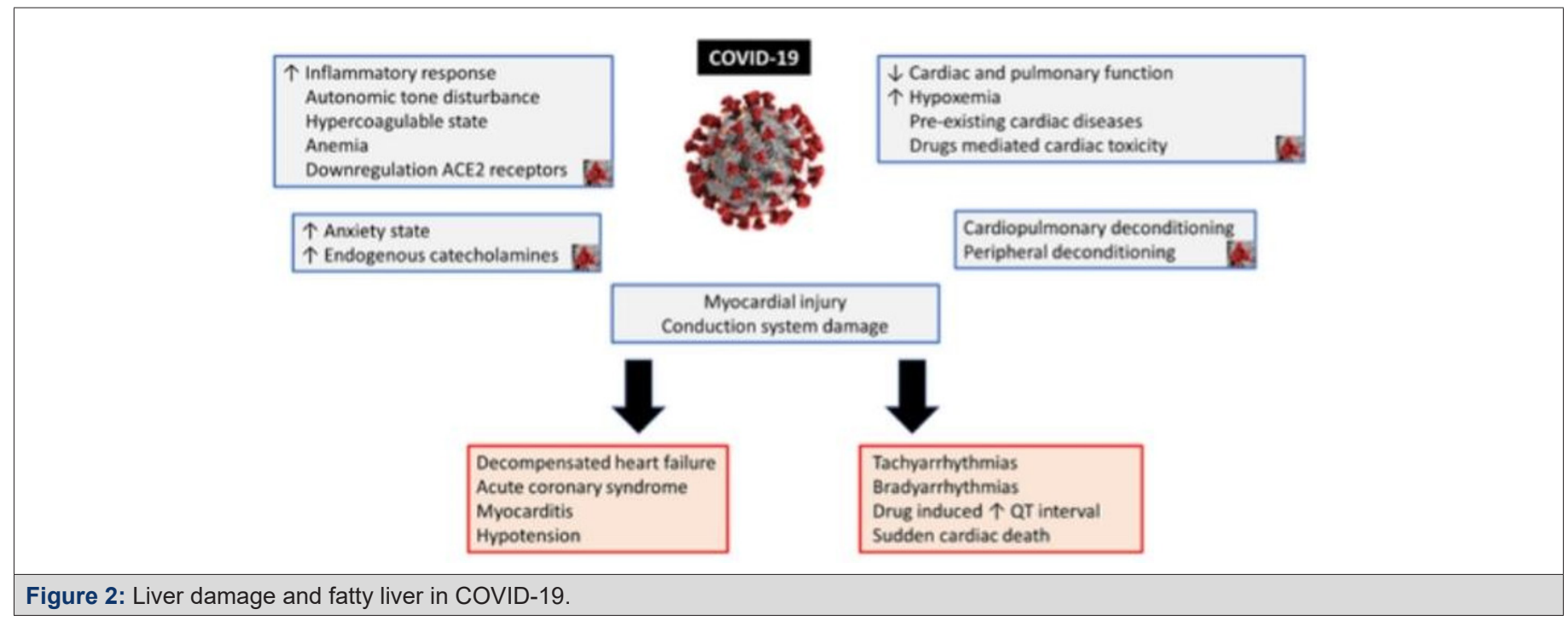

Risk factors such as high BMI [95], obesity [96], blood pressure and especially smoking in NAFLD, MAFLD people are significantly more admitted to the ICU and use mechanical ventilation than healthy people who take COVID-19 [97]. A study of humans with different skin colors showed that people with NASH, NAFLD who develop COVID-19 have a higher incidence of COVID-19 than black people, and that life expectancy increases every year in proportion to the symptoms of COVID-19 becomes more severe [98]. COVID-19 in the acute stages of the disease because SARS-COV-2 infection triggers a CD8 + reaction that attacks and kills virus-infected cells [99]. As a result, they can cause liver disorders [100]. Following the development of liver disorders, such as those with NAFLD, MAFLD, factors such as AST, ALT [101] CRP, Ferritin [99], GGT [102], WBC and neutrophils [103] and ALP [104,105] increase. Some studies show that among the above factors, the higher the levels of TBIL [106] and AST enzymes, the much higher the mortality rate is compared to other enzymes [107]. However, in the field of liver enzymes, there is a difference in research results. Few studies show that ALT and AST levels do not change much [108]. Albumin levels also increase [109]. While many studies have shown that COVID-19 causes significant changes in ALT and AST levels and decreases albumin levels [110], according to studies, it seems that because Numerous studies confirm the change in ALT and AST levels. ALT and AST levels affect the course of COVID-19 disease.

For Various Reasons, Blood Type 0 Has the Lowest and Blood Type a Has the Highest Incidence of Covid- 19

The question of which blood group is most susceptible to COVID
-19 depends on factors such as geography and the frequency of blood groups in that area [111]. According to studies, most people with this virus have a positive blood type A [112-114]. The lowest incidence is related to O-negative [115-118]. This difference must be found in the blood composition of these people [119]. Blood type A has antigen $A$ and antigen $A$ has galactose called saccharide but blood group 0 does not have it $[120,121]$. The coronary factor is SARS-COV-2, which has a strong tendency to bind to carbohydrates, which can be the cause of high blood group A infection with COVID -19 [122]. The SARS-COV-2 receptor in the body is a protein called ACE2 [123,124]. Blood group 0 has more IL_6 than other groups. IL_6 activates ACE inhibitors [125]. One of the causes of death due to coronary heart disease is heart attack and blood clotting [126]. Blood type 0 has a slight tendency to form blood clots [127-129]. This may be due to lower VWF in this blood group [130]. increases during inflammation and causes platelets to bind together [131]. As a result, the mortality of this group is lower than other groups [132134]. Blood type A is more severely affected by COVID-19. This can be due to a decrease in the breakdown of P_SELECTIN and ICAM_1, which will increase inflammation and decrease blood flow [125]. People with anti-A antibodies have been observed to be less likely to develop COVID -19 , but this natural antibody is only resistant to the entry of viruses, not their replication.

\section{Acknowledgement}

None.

\section{Conflicts of interest}

No conflicts of interest. 


\section{References}

1. Azar WS, Njeim R, Fares AH, Azar NS, Azar ST, et al. (2020) COVID-19 and diabetes mellitus: how one pandemic worsens the other. Rev Endocr Metab Disord 21(4): 1-13.

2. Guo W, Li M, Dong Y, Zhou H, Zhang Z, et al. (2020) Diabetes is a risk factor for the progression and prognosis of COVID-19. Diabetes metab res rev 31: e3319.

3. Fang L, Karakiulakis G, Roth M (2020) Are patients with hypertension and diabetes mellitus at increased risk for COVID-19 infection? Lancet Respir Med 8(4): e21.

4. Popkin BM, Du S, Green WD, Beck MA, Algaith T, et al. (2020) Individuals with obesity and COVID-19: A global perspective on the epidemiology and biological relationships. Obes rev 21(11): e13128.

5. Lemyze M, Courageux N, Maladobry T, Arumadura C, Pauquet P, et al. (2020) Implications of Obesity for the Management of Severe Coronavirus Disease 2019 Pneumonia. Critical Care Medicine.

6. Cai Q Chen F, Wang T, Luo F, Liu X, et al. (2020) Obesity and COVID-19 severity in a designated hospital in Shenzhen, China. Diabetes care 43(7): 1392-1398.

7. Lighter J, Phillips M, Hochman S, Sterling S, Johnson D, et al. (2020) Obesity in patients younger than 60 years is a risk factor for Covid-19 hospital admission. Clin Infect Dis 71(15): 896-897.

8. Xu L, Borges MC, Hemani G, Lawlor DA (2017) The role of glycaemic and lipid risk factors in mediating the effect of BMI on coronary heart disease: a two-step, two-sample Mendelian randomisation study. Diabetologia 60(11): 2210-2220.

9. Huang C, Wang Y, Li X, Ren L, Zhao J, et al. (2020) Clinical features of patients infected with 2019 novel coronavirus in Wuhan, China. Lancet 395(10223): 497-506.

10. Zhou F, Yu T, Du R, Fan G, Liu Y, et al. (2020) Clinical course, and risk factors for mortality of adult inpatients with COVID-19 in Wuhan, China: a retrospective cohort study. Lancet 395(10229): 1054-1062.

11. Li B, Yang J, Zhao F, Zhi L, Wang X, et al. (2020) Prevalence, and impact of cardiovascular metabolic diseases on COVID-19 in China. Clin Res Cardiol 109(5): 531-538.

12. Nishiga M, Wang DW, Han Y, Lewis DB, Wu JC (2020) COVID-19 and cardiovascular disease: from basic mechanisms to clinical perspectives. Nat Rev Cardiol 20: 1-6.

13. Portincasa P, Krawczyk M, Smyk W, Lammert F, Di Ciaula A (2020) COVID-19, and non-alcoholic fatty liver disease: Two intersecting pandemics. Eur J clin invest 50(10): e13338

14. Prins GH, Olinga P (2020) Potential implications of COVID-19 in nonalcoholic fatty liver disease. Liver Int 40(10): 2568.

15. Zhou YJ, Zheng KI, Wang XB, Sun QF, Pan KH, et al. (2020) Metabolicassociated fatty liver disease is associated with severity of COVID-19. Liver Int 40(9): 2160-2163.

16. Latz CA, DeCarlo C, Boitano L, Png CM, Patell R, et al. (2020) Blood type and outcomes in patients with COVID-19. Annal hematol 99(9): 21132118.

17. Zuo YY, Uspal WE, Wei T (2020) Airborne Transmission of COVID-19: Aerosol Dispersion, Lung Deposition, and Virus-Receptor Interactions. ACS nano 14(12): 16502-16524.

18. Yu P, Zhu J, Zhang Z, Han Y (2020) A familial cluster of infection associated with the 2019 novel coronavirus indicating possible person-to-person transmission during the incubation period. J infec dise 221(11): 17571761.
19. Soares RD, Mattos LR, Raposo LM (2020) Risk factors for hospitalization and mortality due to COVID-19 in Espírito Santo State, Brazil. Am j trop med hyg 103(3): 1184-1190.

20. Miyazawa D (2021) Why obesity, hypertension, diabetes, and ethnicities are common risk factors for COVID-19 and H1N1 influenza infections. J Med Virol 93(1): 127-128.

21. Acharya D, Lee K, Lee DS, Lee YS, Moon SS (2020) Mortality Rate and Predictors of Mortality in Hospitalized COVID-19 Patients with Diabetes. Healthcare 8(3): 338

22. Brake SJ, Barnsley K, Lu W, McAlinden KD, Eapen MS, et al. Smoking upregulates angiotensin-converting enzyme-2 receptor: a potential adhesion site for novel coronavirus SARS-CoV-2 (Covid-19). J Clin Med $9(3): 841$

23. Albitar O, Ballouze R, Ooi JP, Ghadzi SM (2020) Risk factors for mortality among COVID-19 patients. Diabetes res clin pract 166: 108293.

24. Valencia I, Peiró C, Lorenzo Ó, Sánchez-Ferrer CF, Eckel J, et al. (2020) DPP4 and ACE2 in diabetes and COVID-19: therapeutic targets for cardiovascular complications? Front Pharmacol 11: 1161.

25. Liang JJ, Liu J, Chen Y, Ye B, Li N, et al. (2020) Characteristics of laboratory findings of COVID-19 patients with comorbid diabetes mellitus. Diabetes res clin pract 167: 108351

26. Shenoy A, Ismaily M, Bajaj M, (2020) Diabetes, and covid-19: a global health challenge. BMJ Open Diabetes Res Care 8(1): e001450.

27. Hartmann BJ, Morris E, Goyder C, Kinton J, Perring J, et al. (2020) Diabetes and COVID-19: risks, management, and learnings from other national disasters. Diabetes Care 43(8): 1695-1703.

28. Mozafari N, Azadi S, Mehdi-Alamdarlou S, Ashrafi H, Azadi A, (2020) Inflammation: A bridge between diabetes and COVID-19, and possible management with sitagliptin. Med hypotheses 143: 110111.

29. Iacobellis G (2020) COVID-19 and diabetes: can DPP4 inhibition play a role? Diabetes res clin pract 162: 108125.

30. Verma A, Rajput R, Verma S, Balania VK, Jangra B, (2020) Impact of lockdown in COVID 19 on glycemic control in patients with type 1 Diabetes Mellitus. Diabetes Metab Syndr 14(5): 1213-1216.

31. Singhai K, Swami MK, Nebhinani N, Rastogi A, Jude E (2020) Psychological adaptive difficulties, and their management during COVID-19 pandemic in people with diabetes mellitus. Diabetes Metab Syndr 14(6): 16031605.

32. Joensen LE, Madsen KP, Holm L, Nielsen KA, Rod MH, et al. Educational and Psychological Aspects Diabetes and COVID-19: psychosocial consequences of the COVID-19 pandemic in people with diabetes in Denmark-what characterizes people with high levels of COVID-19related worries?

33. Banerjee M, Chakraborty S, Pal R (2020) Diabetes self-management amid COVID-19 pandemic. Diabetes Metab Syndr 14(4): 351-354.

34. Sankar P, Ahmed WN, Koshy VM, Jacob R, Sasidharan S (2020) Effects of COVID-19 lockdown on type 2 diabetes, lifestyle, and psychosocial health: A hospital-based cross-sectional survey from South India. Diabetes Metab Syndr 14(6): 1815-1819.

35. Mishra Y, Pathak BK, Mohakuda SS, Tilak TV, Sen S, et al. (2020) Relation of D-dimer levels of COVID-19 patients with diabetes mellitus. Diabetes Metab Synd 14(6): 1927-1930.

36. Wang Z, Du Z, Zhu F (2020) Glycosylated hemoglobin is associated with systemic inflammation, hypercoagulability, and prognosis of COVID-19 patients. Diabetes Res Clin Pract 164: 108214.

37. McIntyre HD, Moses RG (2020) The diagnosis and management of gestational diabetes mellitus in the context of the COVID-19 pandemic. Diabetes Care 43(7): 1433-1434. 
38. Moradi F, Ghadiri-Anari A, Enjezab B (2020) COVID-19 and self-care strategies for women with gestational diabetes mellitus. Diabetes Metabolic Syndr 14(5): 1535-1539.

39. Hartmann BJ, Morris E, Goyder C, Kinton J, Perring J, et al. (2020) Diabetes and COVID-19: risks, management, and learnings from other national disasters. Diabetes Care 43(8): 1695-1703.

40. Cunningham JW, Vaduganathan M, Claggett BL, Jering KS, Bhatt AS, et al. (2020) Clinical outcomes in young US adults hospitalized with COVID-19. JAMA internal medicine 181(3): 379-381.

41. Seiglie J, Platt J, Cromer SJ, Bunda B, Foulkes AS, et al. (2020) Diabetes as a risk factor for poor early outcomes in patients hospitalized with COVID-19. Diabetes care 43(12): 2938-2944.

42. Bhandari S, Rankawat G, Singh A, Gupta V, Kakkar S, (2020) Impact of glycemic control in diabetes mellitus on management of COVID-19 infection. Int J Diabetes Dev Ctries 40(3): 340-345.

43. Wu L, Girgis CM, Cheung NW (2020) COVID-19 and diabetes: Insulin requirements parallel illness severity in critically unwell patients. Clin Endocrinol 93(4): 390-393.

44. Chang MC, Park YK, Kim BO, Park D (2020) Risk factors for disease progression in COVID-19 patients. BMC infect dise 20(1): 445.

45. Lippi G, Sanchis GF, Henry BM (2020) Response to: Is newly diagnosed diabetes a stronger risk factor than pre-existing diabetes for COVID-19 severity? J Diabetes 13(2): 179-180.

46. Ceriello A, De Nigris V, Prattichizzo F (2020) Why is hyperglycaemia worsening COVID-19 and its prognosis? Diabetes Obes Metab 22(10): 1951-1952.

47. Hamdy O, Gabbay RA (2020) Early observation and mitigation of challenges in diabetes management of COVID-19 patients in critical care units. Diabetes Care 43(8): 81-82.

48. Li G, Deng Q, Feng J, Li F, Xiong N, et al. (2020) Clinical characteristics of diabetic patients with COVID-19. J diabetes res.

49. Suwanwongse K, Shabarek N (2020) Newly diagnosed diabetes mellitus, DKA, and COVID-19: Causality or coincidence? A report of three cases. J med virol.

50. Sardu C, D’Onofrio N, Balestrieri ML, Barbieri M, Rizzo MR, et al. (2020) Outcomes in Patients with Hyperglycemia Affected by Covid-19: Can We Do More on Glycemic Control? Diabetes Care 43(7): 1408-1415.

51. Pérez-Belmonte LM, Torres-Peña JD, López-Carmona MD, AyalaGutiérrez MM, Fuentes-Jiménez F, et al. (2020) Mortality and other adverse outcomes in patients with type 2 diabetes mellitus admitted for COVID-19 in association with glucose-lowering drugs: a nationwide cohort study. BMC med 18(1): 359.

52. Cuschieri S, Grech S (2020) Obesity population at risk of COVID-19 complications. Glob health, epidemiol genomics 5.

53. Caruso P, Longo M, Signoriello S, Gicchino M, Maiorino MI, et al. (2020) Diabetic foot problems during the COVID-19 pandemic in a tertiary care center: the emergency among the emergencies. Diabetes Care 43(10): 123-124.

54. Linschoten M, Peters S, van Smeden M, Jewbali LS, Schaap J, et al. (2020) Cardiac complications in patients hospitalised with COVID-19. Europ Heart J Acute Cardiov Care 9(8): 817-823.

55. Nattel S (2002) New ideas about atrial fibrillation 50 years on. Nature 415(6868): 219-226.

56. Kir D, Mohan C, Sancassani R (2020) Heart break: an unusual cardiac manifestation of coronavirus disease 2019 (COVID-19). JACC Case Rep 2: $1252-1255$.
57. Peigh G, Leya MV, Baman JR, Cantey EP, Knight BP, et al. (2020) Novel coronavirus 19 (COVID-19) associated sinus node dysfunction: a case series. Eur Heart J-Case Rep 4(FI1): 1-6.

58. Manolis AS, Manolis AA, Manolis TA, Apostolopoulos EJ, Papatheou D, et al. (2020) COVID-19 infection and cardiac arrhythmias. Trends cardiovas med 30(8): 451-460.

59. Babapoor FS, Rasekhi RT, Gill D, Babapoor S, Amanullah A

$(2020)$ Arrhythmia in COVID-19. SN Compr Clin Med 14: 1-6.

60. Ying YZ, Yi TM, Jin YZ, Xiang X (2020) COVID-19 and the cardiovascular system. Nat Rev Cardiol 17(5): 259-260.

61. Yancy CW, Fonarow GC (2020) Coronavirus disease 2019 (COVID-19) and the heart-Is heart failure the next chapter? JAMA cardiology 5(11): 1216-1217.

62. Zhou F, Yu T, Du R, Fan G, Liu Y, et al. (2020) Clinical course, and risk factors for mortality of adult inpatients with COVID-19 in Wuhan, China: a retrospective cohort study. Lancet 395(10229): 1054-1062.

63. Mishra AK, Sahu KK, Lal A, Sargent J (2020) Patterns of heart Injury in COVID-19 and relation to outcome. J Med Virol 92(10): 1747.

64. Tavazzi G, Pellegrini C, Maurelli M, Belliato M, Sciutti F, et al. (2020) Myocardial localization of coronavirus in COVID-19 cardiogenic shock. Eur j heart fail 22(5): 911-915.

65. Gawałko M, Kapłon CA, Hohl M, Dobrev D, Linz D, (2020) COVID-19 associated atrial fibrillation: Incidence, putative mechanisms, and potential clinical implications. Int J Cardiol Heart Vasc.

66. Gori T, Lelieveld J, Münzel T (2020) Perspective: cardiovascular disease and the Covid-19 pandemic. Basic Research in Cardiology 115(3): 32.

67. Bhatla A, Mayer MM, Adusumalli S, Hyman MC, Oh E, et al. (2020) COVID-19 and cardiac arrhythmias. Heart Rhythm 17(9): 1439-1444.

68. Li Y, Li H, Zhu S, Xie Y, Wang B, et al. (2020) Prognostic value of right ventricular longitudinal strain in patients with COVID-19. JACC Cardiovasc Imaging 13(11): 2287-2299.

69. Donoghue M, Hsieh F, Baronas E, Godbout K, Gosselin M, et al. (2000) A novel angiotensin-converting enzyme-related carboxypeptidase (ACE2) converts angiotensin I to angiotensin 1-9. Circ res 87(5): 1-9.

70. Braiteh N, Ur Rehman W, Alom M, Skovira V, Breiteh N, et al. Decrease in acute coronary syndrome presentations during the COVID-19 pandemic in upstate New York. Am heart j 226: 147-151.

71. Matsushita K, Marchandot B, Carmona A, Curtiaud A, El Idrissi A, et al. (2020) Increased susceptibility to SARS-CoV-2 infection in patients with reduced left ventricular ejection fraction. ESC heart failure 8(1): 380389.

72. Bonow RO, Fonarow GC, O'Gara PT, Yancy CW, (2020) Association of coronavirus disease 2019 (COVID-19) with myocardial injury and mortality. JAMA cardiology 5(7): 751-753.

73. Puntmann VO, Carerj ML, Wieters I, Fahim M, Arendt C, et al. (2020) Outcomes of cardiovascular magnetic resonance imaging in patients recently recovered from coronavirus disease 2019 (COVID-19). JAMA cardiology 5(11): 1265-1273.

74. Wang D, Hu B, Hu C, Zhu F, Liu X, et al. (2020) Clinical characteristics of 138 hospitalized patients with 2019 novel coronavirus-infected pneumonia in Wuhan, China. Jama 323(11): 1061-1069.

75. Hasty F, García G, Dávila CH, Wittels SH, Hendricks S, et al. (2020) Heart Rate Variability as a Possible Predictive Marker for Acute Inflammatory Response in COVID-19 Patients. Military Medicine 186(1-2): 34-38.

76. Chen C, Yan JT, Zhou N, Zhao JP, Wang DW (2020) Analysis of myocardial injury in patients with COVID-19 and association between concomitant 
cardiovascular diseases and severity of COVID-19. Zhonghua xin xue guan bing za zhi 48(7): 567-571.

77. Hussain H, Fadel A, Alwaeli H, Guardiola V, (2020) Coronavirus (COVID-19) Fulminant Myopericarditis and Acute Respiratory Distress Syndrome (ARDS) in a Middle-Aged Male Patient. Cureus 12(6): e8808.

78. Knight DS, Kotecha T, Razvi Y, Chacko L, Brown JT, et al. (2020) COVID-19: Myocardial injury in survivors. Circulation 142(11): 1120-1122.

79. Guo T, Fan Y, Chen M, Wu X, Zhang L, et al. (2020) Cardiovascular implications of fatal outcomes of patients with coronavirus disease 2019 (COVID-19). JAMA cardiology 5(7): 811-818.

80. Han H, Xie L, Liu R, Yang J, Liu F, et al. (2020) Analysis of heart injury laboratory parameters in 273 COVID-19 patients in one hospital in Wuhan, China. J Med Virol.

81. Sarin SK, Choudhury A, Lau GK, Zheng MH, Ji D, et al. (2020) Pre-existing liver disease is associated with poor outcome in patients with SARS CoV2 infection; The APCOLIS Study (APASL COVID-19 Liver Injury Spectrum Study). Hepatol int 14(5): 690-700.

82. Yang H, Xu J, Liang X, Shi L, Wang Y, (2021) Chronic liver disease independently associated with COVID-19 severity: evidence based on adjusted effect estimates. Hepatol Int 15(1): 217-222.

83. Zhou YJ, Zheng KI, Wang XB, Sun QF, Pan KH, et al. (2020) Metabolicassociated fatty liver disease is associated with severity of COVID-19. Liver Inter 40(9): 2160-2163.

84. Amin M, (2020) COVID-19 and the liver: overview. Eur J Gastroenterol Hepatol 33(3): 309-311.

85. Biquard L, Valla D, Rautou PE, (2020) No evidence for an increased liver uptake of SARS-CoV-2 in metabolic-associated fatty liver disease. J hepatol 73(3): 717-718.

86. Gao F, Zheng KI, Wang XB, Yan HD, Sun QF, et al. (2020) Metabolic associated fatty liver disease increases COVID-19 disease severity in non-diabetic patients. J Gastroenterol Hepatol 36(1): 204-207.

87. Targher G, Mantovani A, Byrne CD, Wang XB, Yan HD, et al. (2020) Risk of severe illness from COVID-19 in patients with metabolic dysfunctionassociated fatty liver disease and increased fibrosis scores. Gut 69(8): $1545-1547$.

88. Fouad Y, Saad Z, Raheem EA, Moness H, Osman N, et al. (2020) Clinical Validity of the diagnostic criteria for metabolic-associated fatty liver disease: a real-world experience. medRxiv.

89. Iavarone M, D’Ambrosio R, Soria A, Triolo M, Pugliese N, et al. (2020) High rates of 30-day mortality in patients with cirrhosis and COVID-19. J hepatol 73(5): 1063-1071.

90. Wang Y, Liu S, Liu H, Li W, Lin F, (2020) SARS-CoV-2 infection of the liver directly contributes to hepatic impairment in patients with COVID-19. hepatol 73(4): 807-816.

91. Ji D, Qin E, Xu J, Zhang D, Cheng G, (2020) Implication of non-alcoholic fatty liver diseases (NAFLD) in patients with COVID-19: a preliminary analysis. J Hepatol 19(5): 407-408.

92. Yang HY, Jin B, Mao YL, (2020) Liver injury in COVID-19: What do we know now? Hepatobiliary Pancreatic Dis Inter.

93. Li Y, Xiao SY, (2020) Hepatic involvement in COVID-19 patients: Pathology, pathogenesis, and clinical implications. J med virol 92(9): 1491-1494

94. Hashemi N, Viveiros K, Redd WD, Zhou JC, McCarty TR, et al. (2020) Impact of chronic liver disease on outcomes of hospitalized patients with COVID-19: A multicentre United States experience. Liver Inter 40(10): 2515-2521.

95. Hussain A, Vasas P, Shamsi EH, (2020) Letter to the Editor: Obesity as a risk factor for greater severity of COVID-19 in patients with metabolic associated fatty liver disease. Metabolism 108: 154256.
96. Mahamid M, Nseir W, Khoury T, Mahamid B, Nubania A, et al. (2020) Nonalcoholic fatty liver disease is associated with COVID-19 severity independently of metabolic syndrome: a retrospective case-control study. Eur J Gastroenterol Hepatol.

97. Bramante C, Tignanelli CJ, Dutta N, Jones E, Tamariz L, et al. (2020) Non-alcoholic fatty liver disease (NAFLD) and risk of hospitalization for Covid-19. medRxiv.

98. Boeckmans J, Rodrigues RM, Demuyser T, Piérard D, Vanhaecke T, et al. (2020) COVID-19 and drug-induced liver injury: a problem of plenty or a petty point? Arch Toxicol 94(4): 1367-1369.

99. Zhao D, Yao F, Wang L, Zheng L, Gao Y, et al. (2020) A comparative study on the clinical features of COVID-19 pneumonia to other pneumonias. Clin Infect Dis.

100. Zhang C, Shi L, Wang FS, (2020) Liver injury in COVID-19: management and challenges. Lancet Gastroenterol Hepatol 5(5): 428-430.

101. Cai Q, Huang D, Yu H, Zhu Z, Xia Z, et al. (2020) COVID-19: abnormal liver function tests. J Hepatol 73(3): 566-574.

102. Mazzitelli M, Arrighi E, Serapide F, Pelle MC, Tassone B, et al. (2021) Use of subcutaneous tocilizumab in patients with COVID-19 pneumonia. J med virol 93(1): 32-34.

103. Ji D, Zhang D, Yang T, Mu J, Zhao P, et al. (2020) Effect of COVID-19 on patients with compensated chronic liver diseases. Hepatol inter 14(5): 701-710.

104. Hundt MA, Deng Y, Ciarleglio MM, Nathanson MH, Lim JK, (2020) Abnormal Liver Tests in COVID-19: A Retrospective Observational Cohort Study of 1,827 Patients in a Major US Hospital Network. Hepatol 72(4): 1169-1176.

105. Fu Y, Zhu R, Bai T, Han P, He Q, et al. (2020) Clinical Features of COVID-19-Infected Patients with Elevated Liver Biochemistries: A Multicenter, Retrospective Study. Hepatol.

106. Lei F, Liu YM, Zhou F, Qin JJ, Zhang P, et al. (2020) Longitudinal association between markers of liver injury and mortality in COVID-19 in China. Hepatol 72(2): 389-398.

107. Fan Z, Chen L, Li J, Cheng X, Yang J, et al. (2020) Clinical features of COVID-19-related liver functional abnormality. Clin Gastroenterol Hepatol 18(7): 1561-1566.

108. Xie H, Zhao J, Lian N, Lin S, Xie Q et al. (2020) Clinical characteristics of non-ICU hospitalized patients with coronavirus disease 2019 and liver injury: a retrospective study. Liver int 40(6): 1321-1326.

109. Sun Y, Dong Y, Wang L, Xie H, Li B, et al. (2020) Characteristics and prognostic factors of disease severity in patients with COVID-19: The Beijing experience. J autoimmun 112: 102473.

110. El-Shitany NA, El-Hamamsy M, Alahmadi AA, Eid BG, Neamatallah $\mathrm{T}$, et al. (2021) The Impact of ABO Blood Grouping on COVID-19 Vulnerability and Seriousness: A Retrospective Cross-Sectional Controlled Study among the Arab Community. International J Environ Res Public Health 18(1): 276.

111. Wu Y, Feng Z, Li P, Yu Q (2020) Relationship between ABO blood group distribution and clinical characteristics in patients with COVID-19. Clinica Chimica Acta 509: 220-223.

112. Ray JG, Schull MJ, Vermeulen MJ, Park AL, (2020) Association Between $\mathrm{ABO}$ and Rh Blood Groups and SARS-CoV-2 Infection or Severe COVID-19 Illness: A Population-Based Cohort Study. Ann int med 174(3): 308-315.

113. Muñiz-Diaz E, Llopis J, Parra R, Roig I, Ferrer G, et al. (2020) Relationship between the ABO blood group and COVID-19 susceptibility, severity, and mortality in two cohorts of patients. Blood Transfus 19(1): 54-63.

114. Zietz M, Tatonetti NP, (2020) Testing the association between blood type and COVID-19 infection, intubation, and death. MedRxiv. 
115. Esref AR, Solmaz I, Akkoc H, Donmezdil S, Karahan Z, et al. (2020) Association between the $\mathrm{Rh}$ blood group and the Covid-19 susceptibility. Int J Hematol Oncol 30(2): 081-086.

116. Peng M, Huang S, Zhu S, Chen C, Qin J, et al. (2020) Distribution of ABO blood groups and association to low risk of COVID-19 infection in patients.

117. Tanigawa Y, Rivas M, Initial review and analysis of COVID-19 host genetics and associated phenotypes.

118. Rubin $\mathrm{R}$, (2020) Investigating whether blood type is linked to COVID-19 risk. Jama 324(13): 1273.

119. Kolata G, (2020) A heart attack? NO, it was the coronavirus. New York Times.

120. Arshad N, Ashraf S, Sana S, Rehman R, Anwar S, (2020) Blood group association with SARS COVID-19. Hypert 19829001: 724.

121. Fan Q, Zhang W, Li B, Li DJ, Zhang J, et al. (2020) Association between ABO blood group system and COVID-19 susceptibility in Wuhan. Front Cell Infect Microbiol 10: 404.

122. Zhang F, Hughes C, (2020) A caution in association of ABO blood group with COVID-19. Glob Clin Transl Res 2: 51-53.

123. O’Sullivan JM, Ward S, Fogarty H, O’Donnell JS, (2020) "Association between $\mathrm{ABO}$ blood groups and risk of SARS-CoV-2 Pneumonia". Br J Haematol 190(1): 24-27.

124. Liu N, Zhang T, Ma L, Wang H, Li H, (2020) Association between ABO blood groups and risk of coronavirus disease 2019: A protocol for systematic review and meta-analysis. Med 99(33): e21709.

125. AbdelMassih AF, Mahrous R, Taha A, Saud A, Osman A, et al. (2020) The potential use of $\mathrm{ABO}$ blood group system for risk stratification of COVID-19. Med hypotheses 145: 110343.
126. Yamamoto F, Yamamoto M, Muñiz-Diaz E, (2020) Blood group ABO polymorphism inhibits SARS-CoV-2 infection and affects COVID-19 progression. Vox Sanguinis 116(1): 15-17.

127. Scheiner B, Northup PG, Gruber AB, Semmler G, Leitner G, et al. (2020) The impact of ABO blood type on the prevalence of portal vein thrombosis in patients with advanced chronic liver disease. Liver Int 40(6): 1415-1426.

128. Gill JC, Endres-Brooks J, Bauer PJ, Marks WJ, Montgomery RR, (1987) The effect of ABO blood group on the diagnosis of von Willebrand disease. Blood 69(6): 1691-1695

129. Padhi S, Suvankar S, Dash D, Panda VK, Pati A, et al. (2020) ABO blood group system is associated with COVID-19 mortality: an epidemiological investigation in the Indian population. Transfus Clin Biol 27(4): 253-258.

130. Kaiser J, (2020) Found: genes that sway the course of the coronavirus. Science 370(6514): 275-276.

131. Focosi D, Iorio MC, Lanza M, (2020) ABO Blood Group Correlations With COVID-19: Cohort Choice Makes a Difference. Clin Infect Dis 72(11): 919.

132. Hoiland RL, Fergusson NA, Mitra AR, Griesdale DE, Devine DV, et al. (2020) The association of ABO blood group with indices of disease severity and multiorgan dysfunction in COVID-19. Blood advances 4(20): 4981-4989.

133. Valenti L, Villa S, Baselli G, Temporiti R, Bandera A, et al. (2020) Association of $\mathrm{ABO}$ blood group and secretor phenotype with severe COVID-19. Transfusion 60(12): 3067-3070.

134. Barnkob MB, Pottegård A, Støvring H, Haunstrup TM, Homburg K, et al. (2020) Reduced prevalence of SARS-CoV-2 infection in ABO blood group 0. Blood advances 4(20): 4990-4993. 